\title{
Environmental Racism in Indianapolis
}

\author{
The Importance of Connecting with \\ Community Partners
}

BENJAMIN J. CLARK

\section{INTRODUCTION}

"The lead in that soil we found came from an old lead factory that had been in the community. And when they closed, they poured their pollutants into the soil, into the ground, and then it went into the flood... I guess we could just say it went down into the drains, and the city on the streets, and then came back up into our system" (Anonymous, interview by Benjamin Clark, 29 June 2020, transcript, IUPUI Arts \& Humanities Institute).

A longtime resident of the Martindale-Brightwood neighborhood in Indianapolis, an area predominantly populated by Black residents for decades, spoke these words. The quote speaks to the disregard that some companies take toward the environment, especially in majority Black spaces. The experience is but one example of countless Black neighborhoods and communities across the U.S. being polluted by lead factories and other industrial activities (including dry cleaning ${ }^{1}$, oil refineries, manufacturing, and waste disposal).

At the heart of environmental racism is the simple question: Why are Black people disproportionately exposed to pollution in the places where they live? (Aygeman, et al 2016; Beliso-De Jesus 2019; Bullard 2001; Bullard et al 2008; Cole and Foster 2001; Dillon 2014; Henderson and Wells 2021; Mohai et al 2009; Nixon 2013; Pellow 2016; Pulido 2000; Pulido 2015; Pulido 2016; Pulido 2017; Sze 2008; Turner 2016). The question is not new, but has not received enough governmental response when it comes to the experiences of residents in Indianapolis. Meaningful research on environmental racism in Indianapolis has happened but there is much more to be done (see Fuller 2015).

Community-engaged research, grounded in the humanities and social sciences and rooted in ethnographic methods, can provide 
important insights into how environmental racism impacts neighborhoods and communities. I am working on a project called the Anthropocene Household as part of a team of scholars doing community-engaged research at the IUPUI Arts \& Humanities Institute (AHI) ${ }^{2}$. The Anthropocene Household explores the current geological epoch, the Age of Humans, on a local level through the lens of the household in order to understand the experiences, knowledges, and practices associated with environmental change (Angus 2016; McNeill 2014; Moore 2017). In my research, I look at the experiences and understandings specifically related to environmental racism. In this paper I explore two different examples of environmental racism in Indianapolis. One illustrates how white privilege creates environmental racism and the other shows the impact of white supremacy in shaping government response to environmental racism. Both examples demonstrate the value in foregrounding voices and experiences of the people who live in impacted communities. Community-engaged scholarship brings peoples' stories and lived experiences to the forefront. We cannot develop meaningful interventions into environmental racism without understanding the lived experiences and creating space to hear these voices.

A critical element in effective community-engaged scholarship begins with establishing working relationships with community partners. There is a wealth of community knowledge wrought by personal experiences and connecting to community partners means that as researchers we seek to tap into this knowledge. The IUPUI IAHI and Anthropocene Household project partners with two organizations based in Indianapolis. Groundwork
Indy (GWI) ${ }^{3}$, part of a larger national network of Groundwork organizations and based in the Riverside neighborhood, where a groundwater contamination site is located and where lead contamination hotspots are known to exist; GWI assists AHI in distributing free lead testing kits to residents and with recruiting participants in focus groups. The AHI has also developed a partnership with local religious leaders called the Indianapolis Ministerium. Through the Ministerium we have developed a network for distribution of the free lead testing kits. The anonymous results are returned to the household with information about levels of lead in the soil, dust, and water. If unsafe levels are found, the information includes no or low-cost suggestions to reduce risk to their families. In addition, we are working with GWI to conduct focus groups with residents to deepen our understanding of how they define and understand their environment in the context of environmental racism.

\section{WHITE PRIVILEDGE AND ENVIRONMENTAL RACISM}

"As the child's brain is being developed, they say by the third grade the brain has a hard structure around it, but while it doesn't have a hard structure, lead can get into it. Lead, they say, the body thinks lead is milk or calcium so it absorbs it into the brain and it causes damage to you. It shuts it down in certain areas." (Anonymous, interview by Benjamin Clark, 21 April 2020, transcript, IUPUI AHI).

One of the most common and least apparent pollutants is lead, which is found in many places in everyday environments. House paint and water pipes are what most people think of when they hear about lead contamination, but a more

${ }^{1}$ https://storymaps.arcgis.com/stories/4d28f320d66e4a449b2bca01e2491b9b

${ }^{2}$ Visit https://anthropocenes.org/ to learn more about these projects. 
common and troublesome source is lead in the soil around people's homes. The lead found in soil can easily make its way into people's bodies when they play in the yard, plant a garden, eat produce from the garden, or from dirt on their shoes that is tracked into the house. Sometimes the lead comes from a nearby lead refinery, or it got there from particles in leaded fuel exhaust. Often, neighborhoods with the highest concentrations are ones redlined and subsequently bisected by the interstate system. The presence of lead refineries and interstates are often found in predominantly Black neighborhoods (Hentz, Filippelli, et al. 2018, 1). Many of these historical factors contribute to the state of spatial inequities we see in cities across the U.S. (see Ryan 2021). This first example points to the sort of environmental racism that Laura Pulido blames on white privilege, or the social and spatial mobility of white people and the social and spatial immobility of Blacks (Pulido 2015, 2-6).

The Centers for Disease Control and Prevention (CDC) says there is no level of safe lead exposure for children. Children exposed to lead may experience brain and nervous system damage, developmental delays, learning challenges, behavioral issues, and hearing loss. The effects of lead exposure remain long after removal from a child's environment. Lead can linger in a person's body and cause long-term health problems. Children are not the only ones at risk, either. Adults with lead exposure and poisoning can cause high blood pressure, kidney damage, brain damage, miscarriage, and infertility. ${ }^{4}$

Exposure to lead is both a public health crisis and an issue of environmental racism. Unfortunately, many people are simply unaware

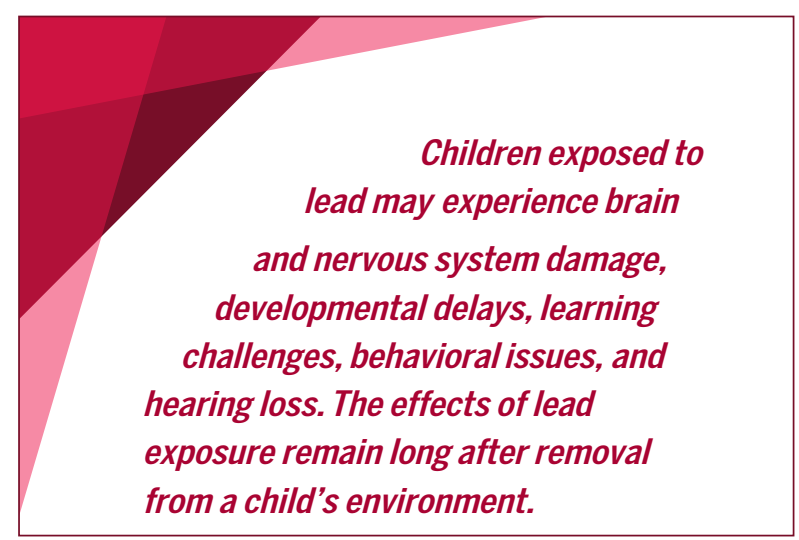

of the presence of lead in their environments and the dangers posed by long-term exposure. Dr. Gabriel Filippelli has done extensive research locally and globally into something he calls the "urban lead exposome." An exposome is the total environmental exposures a person has over a lifetime. Filippelli and his research team lead an ongoing project to map urban lead exposome. They make his findings available to the public as part of a citizen-science project. ${ }^{5}$ Filippelli has worked with Indianapolis' Kheprw Institute and residents from Riverside to gather soil samples from homes and yards. The value of doing citizenscience is that it gathers data on a scale that would otherwise not be possible for an individual researcher and it puts power in the hands of the residents (Filippelli 2018, 9). Filippelli explains that a high lead level in the environment is typically identified through human disease rather than proactive environmental testing. This, he says, is "a harmful and backwards approach to protecting public health" (Filippelli 2018, 1). Lead hotspots usually are identified from a cluster of children with high blood lead levels. Community citizen-science shows the value and effectiveness of testing for the presence of lead before a child

\footnotetext{
${ }^{3}$ https://www.groundworkindy.org/

${ }^{4}$ https://www.cdc.gov/nceh/lead/prevention/health-effects.htm

${ }^{5} \mathrm{https} / / / \mathrm{www} . \mathrm{mapmyenvironment.com/}$
} 
exhibits obvious signs of lead poisoning. "Social, health, and economic cost of [lead] exposure from urban soils is steep-far greater than the cost of targeted remediation of soil [lead] hotspots" (Filippelli 2018, 1).

The IUPUI AHI, as community-engaged scholarship, designed a user-friendly lead testing kit to empower households to test their homes for the presence of lead in the water, soil, and dust. ${ }^{6}$ The results will be sent directly to residents so they can have information to make decisions about how best to address issues the results reveal without fear of recrimination or fines by the government. The goal is to provide the information they need to understand the environment where they live and what actions to take to protect themselves and their loved ones.

In the Indianapolis neighborhood of MartindaleBrightwood, the social justice fight over lead contamination was successfully waged by community. Neighbors came together to form a collaborative to make their concerns heard by local officials, and resulted in the area being designated a Superfund site. From the 1940-60s, the American Lead Corporation, a lead smelting operation in the area, left behind pollution for the residents. The Environmental Protection Agency (EPA) and Indiana Department of Environmental Management (IDEM) worked together to remediate the pollution, but this time the EPA took the lead. Thus far, lead-contaminated soil has been removed and replaced with clean soil at more than 100 residential sites. The cleanup process is not complete, but remains ongoing (Fuller 2015). ${ }^{7}$

In an Anthropocene Household oral history interview with a Martindale-Brightwood resident and one of the leaders of the environmental justice collaborative effort said: “...We found that based on that a lot of people in this neighborhood did gardening. And after we began to look into it a little more and developed a community concern for it, which was our Martindale-Brightwood Environmental Justice Collaborative. We got grants, we did a lot of studies and found out that the soil was not one in which people who didn't know had put gardens in and that kind of thing. So we did a lot of training, got a lot of information, had help from... Well, the EPA had to come out and remediate the yards and put new soil into some of the people's yards. So there were a lot of things that have gone on here since I've been here." (Anonymous, interview by Benjamin Clark, 29 June 2020, transcript, IUPUI AHI.)

The interviewee raised her children in this neighborhood and, even years after her children had grown up and moved on, I could sense her parental anxiety as she spoke. Entire lives were lived in this lead-polluted neighborhood. This resident still proudly calls Martindale-Brightwood her home and was courageous enough to mount what was, at times, a difficult effort to bring social and environmental justice to her neighborhood and community.

Black children tend to have higher blood lead levels than their white counterparts (Waterhouse 2015, 99). Historical factors, including the Great Migration and redlining, have led to neighborhoods with higher-than-average environmental lead levels to be home to majority Black residents. What this points to within Pulido's theoretical framework is lead pollution as an issue of white privilege when it comes to environmental racism. White populations are able to choose and afford to live elsewhere; meanwhile Black residents are socially and economically bound to neighborhoods that have historically been the site of heavy industry and lead smelting,

\footnotetext{
${ }^{6}$ https://anthropocenes.org/lead

${ }^{7}$ https://cumulis.epa.gov/supercpad/SiteProfiles/index.cfm?fuseaction=second.Cleanup\&id=0501643
} 
as in Martindale-Brightwood in Indianapolis (Pulido 2015, 2-6; Fuller 2015, 2-3).

In one oral history interview for the Anthropocene Household project, the informant discussed concerns about exposure to lead that children experience at school through corroded pipes and outdated drinking fountains. Another concern for this interviewee is the lead children are exposed to at home. A concern in particular is lead paint, but lead exposure at home also can come from soil, dust, and water. The main issue with all the lead exposure is long-term health effects, physical and behavioral.

The interviewee described an experience he had while visiting a school that illustrated behavioral challenges caused by lead exposure: "There was a kindergarten teacher that was taking her students from the restroom into the class. There were about maybe twenty-five, twentysix students. There was this small little girl, kindergarten, she was just having a fit. We said, let's go help the teacher. The teacher was able to take the other students in, but the little girl was sliding down the wall... When we approached her, I noticed something yellow in her mouth. 'What's that in your mouth?' She was picking the paint off the wall and eating it. I knew that just from other lead issues and workshops that it causes, if your blood elevation is high, not only brain damage, but your ability to handle your emotions. There are anger issues, comprehension issues, and some issues can become irreversible as the child grows" (Anonymous, interview by Benjamin Clark, 21 April 2020, transcript, IUPUI AHI).

This informant has worked with the local branch of the NAACP and its efforts to raise awareness and take action surrounding lead pollution and exposure in schools and homes-what had him in the school in the first place-but he relayed the story of the young girl "having a fit" and eating paint because he felt it showed the risks and problems children face from lead exposure.

Without governments and corporations funding large-scale cleanup efforts or dramatic policy shifts at all levels, citizens will have to take matters into their own hands to protect their health and wellbeing. As with most public problems, until institutions catch up and reinvent practices and structures embedded in institutional racism, it is important that community members are empowered with good information and the ability to safely self-advocate.

\section{WHITE SUPREMACY AND ENVIRONMENTAL RACISM}

In February 2013 Citizens Energy, a public charitable trust that manages drinking water and other utilities for Indianapolis, notified IDEM about contaminated groundwater (aquifer and wells) in Riverside, a near northwest side neighborhood. IDEM notified the EPA and began evaluating the site for the National Priorities List to trigger the Superfund process..$^{8}$ Superfund is money established to fund long-term expensive projects, and here refers to paying for the cleanup of toxic pollution sites. (The site became known as the Riverside Contaminated Groundwater Site later labeled site 0153). According to public documents from IDEM ${ }^{9}$, it took more than a year to do a site visit to this place known to have contaminated groundwater. In May 2014, IDEM finally visited the area to take water samples. By this time the wells and aquife ${ }^{10}$ were offline and not contributing to the water coming out of people's pipes. However, the dangerous chemicals were still present in the ground. Evidence suggests the water was contaminated by decades

\footnotetext{
${ }^{8}$ https://www.in.gov/idem/cleanups/sites-of-special-interest/site-0153-ground-water-contamination-site/

${ }^{9}$ https://www.in.gov/idem/cleanups/sites-of-special-interest/site-0153-ground-water-contamination-site/site-0153-potential-responsible-party-prp/

${ }^{10} \mathrm{https}$ ///storymaps.arcgis.com/stories/4d28f320d66e4a449b2bca01e2491b9b
} 
of commercial and industrial chemicals seepage into the soil and aquifer and proximity to the polluted White River with its problems related to combined sewer overflow. Not coincidentally, this section of the city has been predominantly low income, working class, Black residents for decades.

"They tried to convince us the whole time, 'Your drinking water is safe. This isn't the case of Flint, Michigan. Blah, blah, blah.' I'm like, 'I'm not stupid. I understand that Citizens Energy is gonna make sure the drinking water is safe, but what about everybody in the neighborhood that has basements. What about these chemicals leaching into the ground and vapor intrusion in the people's basements? How long has this been going on? Do they need treatment now? Have you tested anybody's basements?" (Anonymous, interview by Abbey Chambers, 25 July 2018, transcript, IUPUI AHI).

The Riverside resident provides a clear window into the challenge posed by site 0153 . The city, state, property, and business owners on the one hand and the residents of Riverside on the other, and tension over how best to resolve the groundwater contamination. This interviewee had deep concerns that residents were not being told the complete story and that the extent of the problem and potential threats to health and safety were papered over.

Site 0153 illustrates the white supremacy in environmental racism wrought by governmental indifference, favoring private interests over public good, government agencies hamstrung by lack of funding and toothless public policy, and a lack of enforcement of environmental policies, or any sense of urgency. White Supremacy describes the kind of environmental racism that creates differential protection and unequal enforcement of public policy. Environmental injustice is readily apparent in the dangers posed to Blacks by corporations and governments collaborating to maintain regulatory noncompliance. Even with laws and regulations in place, governments let corporations off the hook when adhering to regulations in any meaningful way (Pulido 2015, 1-6; Melamed 2015; Pellow 2016; Rodgers and O’Neill 2012; Rosa and Diaz 2019; Sampson and Winter 2016; Turner 2016; Waterhouse 2016).

Public debate focused whether to label site 0153 a Superfund site and allow the EPA to fund and manage the mitigation project or to have IDEM take over clean-up efforts. Property owners feared the Superfund label would hurt property values, so community leadership (mostly in the form of the Riverside Civic League), 16 Tech "urban innovation district, ${ }^{11}$ " with federal and state authorities decided to hand the project over to IDEM. The resident quote speaks to the unease and distrust that Riverside residents had of IDEM.

What site 0153 offers in understanding white supremacy and environmental racism is how it provides a glimpse into various responses from community members as the story folds. Residents have a sense of connection and attachment to their neighborhood, even if they do not have a financial investment other than paying rent. Statements and public comments below are found on EPA's website for the Riverside Groundwater Contamination Site. ${ }^{12}$ This website's public comments are part of the remediation process for Superfund sites. From the comments one can sense tension between opposing sides of the argument over the Superfund label and ultimately

\footnotetext{
${ }^{11} 16$ Tech is a $\$ 360$ million plan for redevelopment of 60 acres of land within the Site 0153 project boundary into 100,000 square feet of research and office space.

${ }^{12} \mathrm{https}$ //cumulis.epa.gov/supercpad/SiteProfiles/index.cfm?fuseaction=second.scs\&id=0510936\&doc=Y\&colid=33747\&region=05\&type=SC
} 
the most efficacious resolution. The quotes illustrate priorities of the person or organization.

From 16 Tech: "The Riverside neighborhood in which 16 Tech will be located, along with several other surrounding neighborhoods, welcomes this development and played an instrumental role in 16 Tech securing bond financing from the City of Indianapolis and the City-County Council last year." (from Indiana Biosciences Research Institute and 16 Tech Community Corporation to Region 5 U.S. Environmental Protection Agency, 5 September 2016).

From the Greater Indianapolis NAACP Public Statement: "The Greater Indianapolis NAACP Branch 3053 is actively working with local public officials, neighborhood residents, clergy and minority organizations in support of the local plan and the removal of the site from NPL consideration... As the Greater Indianapolis NAACP Branch 3053 believes with continuous collaboration with the State, City of Indianapolis and Citizens Energy Group we are able to ensure safe drinking water. We look forward to ongoing investigations for remediation to correct potentially contaminated sites that could be contributing to the groundwater contamination" (Chrystal Ratcliffe, President, Greater Indianapolis NAACP Branch 3053, 7 September 2016).

From the Riverside Civic League: "The Riverside Neighborhood is at the brink of rising from decades of disregard and we the residents cannot afford to go backwards by becoming a superfund site especially when the reported contaminants can be addressed by a Local Alternative Plan that we help mold and would definitely oversee. Once the community was notified, we came together to hear the voices, fears and concerns of our residents then immediately sought out answers so we could weigh the heaviness of this choice." (Peggy Gamlin, President, Riverside Civic League, 12 September 2016).
There are pages of public comments, many posted anonymously. To give a sense for public sentiment, I share a sampling of comments on Superfund designation:

"It would be wrong to designate this neighborhood as a Superfund... The Riverside neighborhood has been a victim of terrible disinvestment and redlining in the past. The neighborhood has been a great partner to the new 16 Tech development occurring in the southern region of Riverside. A listing on the NPL would halt or end entirely that development and all the work that has been done to revitalize this neighborhood" (Anonymous, 27 June 2016).

"As a business owner in this area for thirty years, I believe it would be more destructive to the wellbeing of this neighborhood to designate this area as a Superfund Site than to allow for alternative means of resolution of the purported water contamination... The Riverside neighborhood has seen limited to non-existent investment in the infrastructure or neighborhood amenities for decades. The neighborhood now has a potential investor with the new 16 Tech development that has been proposed..." (Anonymous, 25 August 2016)

A comment from someone who just wants something to happen and does not support one remediation over another: "I am a homeowner in the NW area of Indianapolis. I would truly appreciate clean water, clean fertile soil, to have my family be safe. I would like a remedy that does the poor and elderly people justice" (Anonymous, 12 September 2016).

Likewise, residents and tenants deeply invested in the community who wanted the Superfund label desired financial support from the federal government during the Obama Administration. Residents were skeptical of IDEM's leadership under Governor Pence and the agency's willingness and ability to follow through on 
mitigation. It has been over eight years since EPA and IDEM became aware of the problem and with little progress on contamination removal.

Public comments posted on the EPA website that support Superfund designation include:

"I live at 14th and Delaware and I am very concerned about the water quality in inner city Indianapolis. I sincerely hope the EPA will approve a Superfund to help with this cleanup" (Anonymous, 30 August 2016).

"The community needs resources from the EPA to test our own water. These resources might include financial resources for community organization and education. IDEM is not a trusted entity by any Hoosier I have spoken with.” (Anonymous, 30 August 2016).

"After attending a presentation at the Kheprw Institute that included presentations by EPA staff, and learning of the IDEM related to environmental cleanup (which is very poor), I strongly feel the EPA should designate Riverside as a Superfund site. Economic development is important, but the fundamental consideration must be the health of the people affected by the water supply. The number of people involved means this should be done correctly and as quickly as possible, and IDEM has a history that indicates it is not up to the job. Please have the EPA deal with this as a Superfund site." (Anonymous, 31 August 2016).

Now offline the wells no longer contribute to the city's water supply, but remaining concern is vapor intrusion since the chemicals remain in the environment. IDEM site 0153 updates suggest mitigation remains in the planning phase. They only recently identified the method they plan for cleanup efforts.

Anthropocene Household Oral History interview, Riverside resident: "I do think a big push back from homeowners is the idea of stigma of a neighborhood leading to reducing property values and derailing the development plans and projects for the neighborhood. Whereas I think that that was not the first lens we should use to make that decision, or at least have that decision made for the community by these institutional players who're invested in a certain outcome... The priority was to protect the investment. And it was framed through this lens of local control and stigma that then leads to lowering property values... Because nothing has changed about the environmental circumstances... with the fact that IDEM is doing the cleanup. But the properties are also becoming less and less affordable in the neighborhood, and are quickly rising beyond what I can afford and what others in the community can afford." (Anonymous, interview by Benjamin Clark, 23 September 2020, transcript, IUPUI AHI).

Having IDEM manage the cleanup, keeping it off the Superfund list, would allow property values in this neighborhood to rise and could protect the investments of homeowners, businesses, and 16 Tech. One resident described how IDEM initially made the call to have the EPA come in and manage the cleanup but after getting pushback from the developers of an area "urban innovation district" had concerns about a Superfund site.

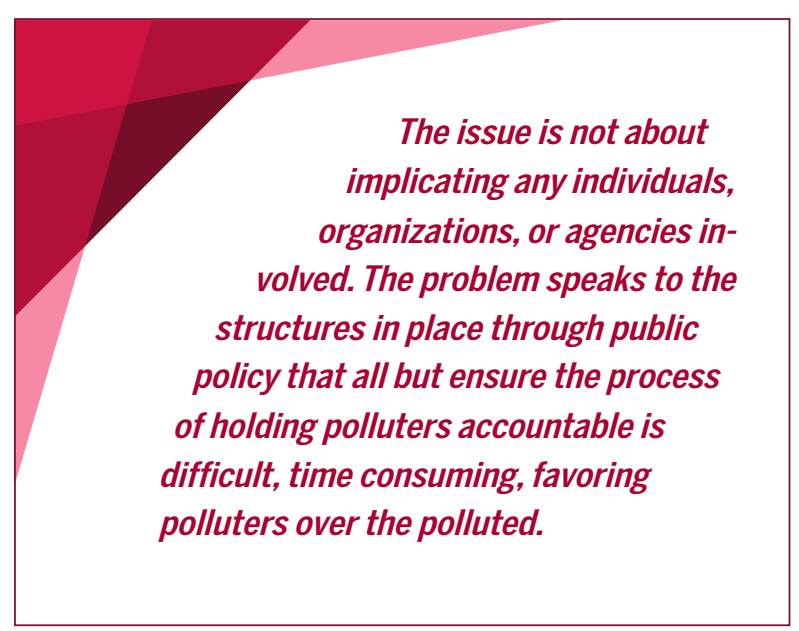


Anthropocene Household Oral History interview, Riverside resident: "I learned that The Indiana Department of Environmental Management is not only incompetent, but they're dirty. They're liars. They try to play the community for fools..." (Anonymous, interview by Abbey Chambers, 25 July 2018, transcript, IUPUI AHI).

Distrust that their health and wellbeing are not being looked after, but rather the interests of property owners, business, and corporations invested in gentrification won. The resident explains how IDEM officials in a public meeting seemed to purposely misrepresent the presence of chemicals in the environment-not only the levels but also the types of chemicals-done in favor of development and gentrification, not to protect the health of residents.

Site 0153 has been stuck in a bureaucratic malaise for years. Meanwhile, area low income, working class Black residents live with dangerous levels of chemicals in their environment. Citizens Energy assures the community that the water is safe to drink. The water meets the standards set forth by the Safe Drinking Water Act. Nevertheless, the chemicals remain in the environment where children and adults live every day.

The issue is not about implicating any individuals, organizations, or agencies involved. The problem speaks to the structures in place through public policy that all but ensure the process of holding polluters accountable is difficult, time consuming, favoring polluters over the polluted, resulting in slow cleanup, ultimately rooted in systems of oppression from white supremacy (Pulido 2015; Pulido 2016; Pulido 2017).

An IDEM project manager asked in an Anthropocene Household oral history interview who he identified as his customers, his constituents, said: "Customers would be environmental attorneys, environmental consultants, their clients, so oftentimes dry

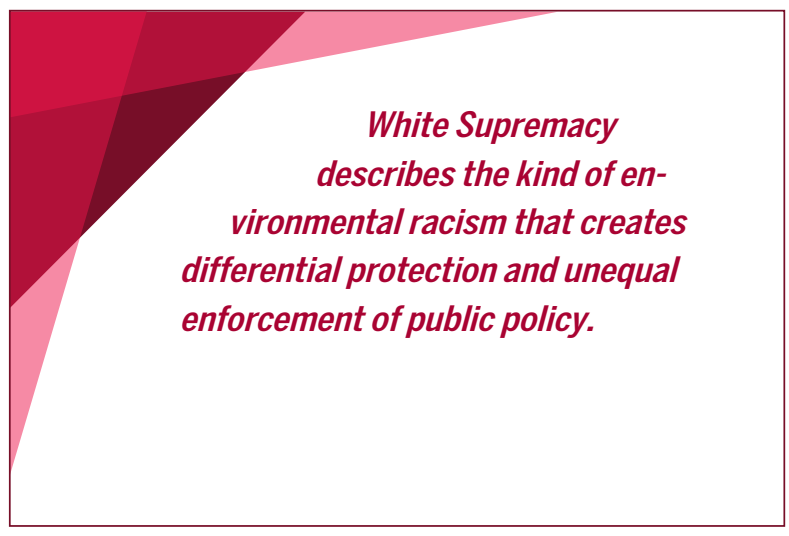

cleaner operators, property owners they're interested in redevelopment or cleanup of their property for redevelopment, industry companies that have operated there that have had releases of contamination that either need to clean it up under regulation or are seeking or desiring to get it cleaned up for business purposes, so those are the primary customers or clients or people that we deal with." (Anonymous, interview by Abbey Chambers and Stacia Murphy, 19 July 2018, transcript IUPUI AHI).

He clearly states his customers are the polluters. What is absent is any acknowledgement or reference to the people who live in the polluted and contaminated neighborhoods. Instead, he says that their customers did the polluting. As a state agency funded by tax dollars, something seems upside down in his response, but speaks to the ways that the structures of public policy fail to meaningfully improve environmental conditions of lower income Black neighborhoods.

Anthropocene Household Oral History interview, Riverside resident: "The way IDEM works, they don't have a lot of teeth to hold companies accountable. They tried to work with them and put them into a voluntary program, which again, there are long delays between steps and just hoping people do the right thing and trying to occasionally follow up with them." (Anonymous, interview by Benjamin Clark, 23 September 2020, transcript, IUPUI AHI). 


\section{CONCLUSION}

Site 0153 is an example of regulatory noncompliance wrought by white supremacy that results in environmental racism. The processes move slowly and tend to favor private interests over public good. Subtle and multifaceted processes contribute to this slowness and the power dynamics at play that certainly deserve deeper examination. What ends up happening is that lower income Black and Brown communities are forced to live in polluted environments while the bureaucratic processes play out to favor polluters over the polluted. What is challenging about identifying and calling out white supremacy is that it is so ingrained into our hegemonic white cultural milieu and can be difficult to detect. It can easily fly under the radar. That is the value of Pulido's theoretical framework as it allows us to illuminate the issues more clearly. The regulatory culture around noncompliance is "mutually constituted by the racial formation" (Pulido 2015, 2).

There are many ways to approach this issue of environmental racism. At the IUPUI Arts \& Humanities Institute and the Anthropocene Household project, we believe that doing community-engaged scholarship is helpful and meaningful for forming necessary interventions, co-creation of knowledge, and working with impacted citizens to understand and contribute to finding solutions. Pulido explains that there is ample research that shows how "environmental hazards follow along racial lines but also many of the meta-processes... such as industrialization, urbanization, and capitalism, are racialized" (Pulido 2018, 117). What is fundamentally important about Pulido's point is that the environmental hazards and meta-processes play a role in "determining who lives and who dies" (Pulido 2018, 117).

Environmental racism is at the intersection of systemic racism, systemic poverty, and ecological devastation. If we want to achieve environmental justice, then we are going to have to recognize and call out acts of environmental racism in all its various forms [We're] hoping people do the right thing and trying to occasionally follow up with them." (Anonymous, interview by Benjamin Clark, 23 September 2020, transcript, IUPUI AHI). 


\section{References}

Agyeman, Julian, David Schlosberg, Luke Craven, and Caitlin Matthews. "Trends and Directions in Environmental Justice: From Inequity to Everyday Life, Community, and Just Sustainabilities." Annual Review of Environment and Resources 41, no. 1 (2016):32140.

Angus, lan. Facing the Anthropocene: fossil capitalism and the crisis of the earth system. New York: Monthly Review Press, 2016.

Beliso-De Jesus, A. M. a. J. P. "Introduction: Special Section: Anthropology of White Supremacy." American Anthropologist 122, no. 1 (2019): 65-75.

Bullard, Robert D. "Environmental Justice in the 21st Century: Race Still Matters." Phylon (1960-) 49, no. 3/4 (2001): 151-71.

Bullard, Robert D., Paul Mohai, Robin Saha, and Beverly Wright. "TOXIC WASTES AND RACE AT TWENTY: WHY RACE STILL MATTERS AFTER ALL OF THESE YEARS." Environmental Law 38, no. 2 (2008): 371-411.

Cole, Luke W., and Sheila R. Foster. From the Ground Up: Environmental Racism and the Rise of the Environmental Justice Movement. First Edition. New York: NYU Press, 2001.

Dillon, Lindsey. "Race, Waste, and Space: Brownfield Redevelopment and Environmental Justice at the Hunters Point Shipyard." Antipode 46, no. 5 (2014): 1205-21.

Filippelli, Gabriel M., Jessica Adamic, Deborah Nichols, John Shukle, and Emeline Frix.

"Mapping the Urban Lead Exposome: A Detailed Analysis of Soil Metal Concentrations at the
Household Scale Using Citizen Science." International Journal of Environmental Research and Public Health 15, no. 7 (2018)

Fuller, Trevor. Environmental Justice and Activism in Indianapolis. Lanham: Lexington Books, 2015.

Harvey, David. A Brief History of Neoliberalism. Oxford: Oxford University Press, 2005.

Henderson, Sheree and Rebecca Wells. "Environmental Racism and the Contamination of Black Lives: A Literature Review." Journal of African American Studies (2021).

Hentz, Emily, Gabriel Filippelli, et al. "Assessing lead exposure sources at the property scale in Indianapolis." Proceedings of Indiana University Medical Student Program for Research and Scholarship, vol. 1, no. 1, 2018.

McNeill, John Robert, and Peter Engelke. The Great Acceleration: An Environmental History of the Anthropocene Since 1945. Cambridge, MA: The Belknap Press of Harvard University Press, 2014.

Melamed, Jodi. "Racial Capitalism." Critical Ethnic Studies 1, no. 1 (2015): 76-85.

Mohai, Paul, David Pellow, and J. Timmons Roberts. "Environmental Justice." Annual Review of Environment and Resources 34 , no. 1 (2009): 405-30.

Moore, Jason W. "The Capitalocene, Part I: on the nature and origins of our ecological crisis." The Journal of Peasant Studies. 44:3 (2017): 594-630.

Nixon, Rob. Slow Violence and the Environmentalism of the Poor. Cambridge: Harvard University Press, 2013.
Pellow, David N. "Towards a Critical Environmental Justice Studies: Black Lives Matter as an Environmental Justice Challenge." Du Bois Review: Social Science Research on Race 13, no. 2 (2016).

Perry, Marc D. "Who Dat?." City and Society, vol. 27, no. 1 (2015): 92-114.

Pulido, Laura. "Rethinking Environmental Racism: White Privilege and Urban Development in Southern California." Annals of the Association of American Geographers 90, no. 1 (2000): 12-40.

- - - "Geographies of Race and Ethnicity I: White Supremacy vs White Privilege in Environmental Racism Research." Progress in Human Geography 39, no. 6 (2015): 809-17.

--_. "Geographies of Race and Ethnicity II: Environmental Racism, Racial Capitalism and State-Sanctioned Violence." Progress in Human Geography 41, no. 4 (2017): 524-33.

--_. 2016. "Flint, Environmental Racism, and Racial Capitalism." Capitalism Nature Socialism, 27:3 (2016), 1-16.

Robbins, Paul. Political Ecology: A Critical Introduction. Malden, MA: Blackwell Pub., 2004.

Rodgers, Dennis, and Bruce O'Neill. "Introduction: Infrastructural Violence: Introduction to the Special Issue." Ethnography 13, no. 4 (2012): 401-12.

Rosa, Jonathan and Vanessa Diaz. "Raciontologies: Rethinking Anthropological Accounts of Institutional Racism and Enactments of White Supremacy in the United States." American Anthropologist, Vol. 122, No. 1 (2019): 120-132.
Ryan, Jordan. "Spatial Inequities in Indianapolis." Creative Mornings. 10 May 2021. https:// creativemornings.com/talks/jordan-ryan/1.

Sampson, Robert J., and Alix S. Winter. 2016. “The Racial Ecology of Lead Poisoning: Toxic Inequality in Chicago Neighborhoods, 1995-2013". Du Bois Review: Social Science Research on Race 13 (2):261-283

Sze, Julie and Jonathan London. "Environmental Justice at the Crossroads." Sociology Compass Vol. 2, no. 4 (2008): 1331-1354

Turner, Rita. “The Slow Poisoning of Black Bodies: A Lesson in Environmental Racism and Hidden Violence." Meridians: Feminism, Race, Transnationalism 15, no. 1 (2016): 189-204

Waterhouse, Carlton M., and Ravay Smith. "The Lingering Life of Lead Pollution: An Environmental Justice Challenge for Indiana." Indiana Law Review 49 (2016): 99. 